Illinois State University

ISU ReD: Research and eData

Theses and Dissertations

4-10-2017

\title{
Intervention Effects of an Eating Disorder Prevention Program Utilized by a Public University
}

Krista B. DeCeault

Illinois State University, kbdecea@ilstu.edu

Follow this and additional works at: https://ir.library.illinoisstate.edu/etd

Part of the Human and Clinical Nutrition Commons

\section{Recommended Citation}

DeCeault, Krista B., "Intervention Effects of an Eating Disorder Prevention Program Utilized by a Public University" (2017). Theses and Dissertations. 721.

https://ir.library.illinoisstate.edu/etd/721

This Thesis is brought to you for free and open access by ISU ReD: Research and eData. It has been accepted for inclusion in Theses and Dissertations by an authorized administrator of ISU ReD: Research and eData. For more information, please contact ISUReD@ilstu.edu. 


\section{INTERVENTION EFFECTS OF AN EATING DISORDER PREVENTION}

\section{PROGRAM UTILIZED BY A PUBLIC UNIVERSITY}

\section{Krista B. DeCeault}

\section{Pages}

Background: Negative body image, disordered eating, and eating disorders affect large numbers of young women each year. The use of dissonance-based eating disorder prevention programs in college-aged women has been shown to improve how women feel about their bodies and better equip women for challenging stereotypes that exist in the culture today.

Objective: The purpose of this study was to evaluate the intervention strategies of the "Body Project," an eating disorder prevention program, and assess the effectiveness on reducing five eating disorder risk factors; thin-ideal internalization, diet restraint, body dissatisfaction, negative affect, and eating disorder symptoms.

Design: Two years of pre- and post-Body Project survey data were utilized to examine the intervention effects of the Body Project eating disorder prevention program.

Participants: Female college students at a large public university were welcome to participate in the Body Project. Data was collected from a total of 51 female college students who participated in the workshop in a two-year period.

Results: Statistical analysis revealed a significant improvement in all five eating disorder risk factors assessed after participants participated in the Body Project. Ideal-thin internalization decreased by $22.7 \%$ ( $7.26 \pm 6.48$ points $)$, dieting behaviors decreased by $16.6 \%(6.649 \pm 7.392$ points), body dissatisfaction decreased by $13.5 \%(-4.863 \pm 7.001$ points $)$, negative affect 
decreased by $12.4 \%$ ( $9.931 \pm 11.586$ points $)$, and eating disorder symptoms related to body image decreased by $7.1 \%(-2.549 \pm 7.198$ points $)$. In addition, there were strong positive correlations between pre-and-post eating disorder risk factors, and these relationships changed and weakened from pre- to post-survey. Finally, after adjustment for BMI, there was a statistically significant difference in body dissatisfaction scores from pre-survey to postsurvey, $\mathrm{F}=4.544, \mathrm{p}<.05$. Results showed that body dissatisfaction was significantly improved in participants with higher BMIs (overweight/obese classification) compared to participants with lower BMIs (BMI Group 1), a mean difference of 3.692 points, $\mathrm{p}<.05$.

Conclusions: Eating disorder risk factors significantly decreased after participating in the Body Project program. BMI did not have a direct effect on 4 of the 5 eating disorder risk factors, but there was a correlation between BMI and body dissatisfaction. More research needs to be conducted that examines the long-term effects of eating disorder prevention programs and the relationship between BMI and intervention impacts.

KEYWORDS: Eating Disorder Prevention, Body Image, University, Risk Factors 


\title{
INTERVENTION EFFECTS OF AN EATING DISORDER PREVENTION PROGRAM UTILIZED BY A PUBLIC UNIVERSITY
}

KRISTA B. DECEAULT

\author{
A Thesis Submitted in Partial \\ Fulfillment of the Requirements \\ for the Degree of \\ MASTER OF SCIENCE \\ Department of Family and Consumer Sciences \\ ILLINOIS STATE UNIVERSITY
}


(C) 2017 Krista B. DeCeault 
INTERVENTION EFFECTS OF AN EATING DISORDER PREVENTION

PROGRAM UTILIZED AT A PUBLIC UNIVERSITY

KRISTA B. DECEAULT

COMMITTEE MEMBERS:

Jennifer Barnes, Chair

Tammy Harpel

Julie Schumacher 


\section{ACKNOWLEDGMENTS}

This research would not have been possible without the encouragement and support of many individuals. I would like to thank my supportive committee chair, Dr. Jennifer Barnes, for her continuous assistance, encouragement, and profound patience throughout this project. Additionally, I would like to express my gratitude for my committee members, Dr. Julie Schumacher, and Dr. Tammy Harpel. I am also grateful for the time and assistance provided to me by Jenni Thome and the Illinois State faculty members that implement the Body Project. I would like to say thank you to my family, friends, and dietetic internship preceptors for their encouragement and excitement towards my research. Finally, I would like to extend a special thank you to my lovely mother who called me constantly to make sure I was working on my thesis. Honestly, I could not have completed this project without her encouragement.

K. B. D. 


\section{CONTENTS}

Page

ACKNOWLEDGMENTS

CONTENTS

ii

TABLES

iv

CHAPTER

I. JOURNAL ARTICLE 1

Introduction 1

$\begin{array}{ll}\text { Methodology } & 4\end{array}$

$\begin{array}{ll}\text { Participants } & 4\end{array}$

Body Project Intervention $\quad 5$

$\begin{array}{ll}\text { Data Collection } & 6\end{array}$

$\begin{array}{ll}\text { Measures } & 6\end{array}$

Data Analysis $\quad 9$

$\begin{array}{ll}\text { Results } & 10\end{array}$

$\begin{array}{ll}\text { Descriptive Statistics } & 10\end{array}$

$\begin{array}{ll}\text { Improvement of Risk Factors } & 10\end{array}$

Relationships Between Risk Factors $\quad 11$

$\begin{array}{ll}\text { Body Mass Index } & 12\end{array}$

$\begin{array}{ll}\text { Discussion } & 13\end{array}$

$\begin{array}{ll}\text { Intervention Effects } & 13\end{array}$

Correlations Between Risk Factors 14

$\begin{array}{ll}\text { Body Mass Index } & 16\end{array}$

$\begin{array}{ll}\text { Limitations } & 17\end{array}$ 
$\begin{array}{ll}\text { Conclusion } & 18\end{array}$

$\begin{array}{ll}\text { Future Directions } & 20\end{array}$

$\begin{array}{ll}\text { References } & 21\end{array}$

$\begin{array}{ll}\text { Tables } & 24\end{array}$

II. EXTENDED LITERATURE REVIEW 26

Eating Disorder Prevalence 26

Eating Disorder Prevention Strategies $\quad 27$

Healthy Weight Interventions 28

$\begin{array}{ll}\text { Dissonance Interventions } & 30\end{array}$

$\begin{array}{ll}\text { Effect on BMI } & 34\end{array}$

$\begin{array}{ll}\text { Conclusions } & 36\end{array}$

$\begin{array}{ll}\text { References } & 38\end{array}$

APPENDIX A: BODY PROJECT PRE/POST SURVEY 45

APPENDIX B: RECRUITMENT LETTER 47 


\section{TABLES}

Table

Page

1. Paired Samples $t$-tests Comparing Eating Disorder Risk Factor Differences from Pre-to-Post Survey

2. Pearson's Correlation Pre-Survey Results

3. Pearson's Correlation Post-Survey Results

4. BMI ANCOVA Results 
CHAPTER I

JOURNAL ARTICLE

\section{Introduction}

Eating disorders have the highest mortality rate of all psychiatric conditions (Smink, et. al., 2012), yet only 1 in 10 people seek out treatment (Arcelus et. al., 2011). The stigma associated with mental health treatment, lack of treatment options that are easily accessible, and high costs for treatment are a few major barriers to treatment (Henderson et. al., 2012). According to the National Eating Disorder Association, 20 million women in America have suffered from an eating disorder at some point in their life ("What are Eating Disorders," 2016). A questionnaire-based study found that $25 \%$ of college students use behaviors associated with bulimia nervosa such as binging and purging, in an attempt to control their weight (Renfrew Center Evaluation, 2003). Collegiate women are a particularly vulnerable population for developing eating disorder symptoms and poor body image due to many factors (Hoerr, et. al., 2002). American media floods women with unrealistic beauty messages that imply that having the perfect body will provide oneself with happiness and success. It is not surprising that $76 \%$ of college females at a large public university identified as having a strong desire to lose weight (Walsworth \& Perkins, 2015). Furthermore, negative body image can develop or worsen in women who internalize unrealistic beauty standards (Hawkins, et. al., 2004). This is alarming, as women with negative body image are more likely to experience isolation, depression, low selfesteem, and obsessions about weight loss, and are at greater risk for developing eating disorders (Hawkins, et. al., 2004).

Various studies have found positive outcomes for the Body Project, a dissonance-based eating disorder prevention program, on high school and college campuses that focuses on 
reducing thin-ideal internalization (Body Project Support). The Cognitive Dissonance Theory suggests that people strive for the internal and external consistency of their cognitions (i.e., thoughts, emotions, beliefs). When inconsistency occurs between beliefs and behaviors, dissonance increases and causes discomfort. To decrease dissonance, people will either change their behaviors or beliefs to restore internal comfort. Body Project participants are lead to generate cognitive dissonance by openly challenging the thin-ideal, meaning the concept that women should maintain an ideally slim body (Hendricks \& Burgoon, 2003). Challenging participants to verbally critique thin-ideal messages that are constantly projected by the media (and family, friends, etc.) should hypothetically generate a cognitive dissonance effect and cause a change in attitudes to match their actions.

The Dual Pathway Model, developed by Stice et. al. (2004), illustrates a model of bulimic behavior development. The model shows that pressures to be thin and thin-ideal internalization lead to body dissatisfaction, which causes either dietary restraint or negative affect. These two factors ultimately lead to the onset of bulimia. The Body Project uses the Dual Pathway model as a framework for its intervention program.

The Body Project Collaborative is an outreach program created by Dr. Stice and Dr. Carolyn Becker in 2012 that provides training opportunities for college students, faculty, and community members to become peer-facilitators and implement the workshops in various settings. High schools and universities most often utilize the program, as it was developed specifically for adolescent girls and young women. The Body Project workshops aim to help reduce the pursuit of thinness and challenge the culturally created thin-ideal that women are expected to strive for. Challenging the thin-ideal is reached in the workshops through verbal, written, and behavioral exercises. In addition to reducing dissonance, participants should be able 
to better identify sociocultural messages and reject them, consequently improving body image and decreasing eating disorder risk factors and behaviors (Body Project Support).

Previous studies that analyzed the Body Project outcomes provided strong evidence supporting the assumption that reducing ideal-thin internalization will reduce eating disorder risk factors, but no recent studies have evaluated the intervention effects of the Body Project led by peer-facilitators at through Illinois State University. The current study is an effectiveness trial, which is important because it tests the intervention effects that the Body Project produces under real-world conditions (Stice, et al., 2009). Conducting periodic effectiveness trials on programs that have shown positive outcomes from previous effectiveness trials is crucial to validate the continual success of programs over time. Additionally, fewer studies have investigated the intervention effects on eating disorder risk factors when controlling for participant body mass index (BMI).

The purpose of this study was to evaluate the intervention effects that Body Project workshops at Illinois State University had on participants' eating disorder risk factors (thin-ideal internalization, diet restraint, body dissatisfaction, negative affect, and eating disorder symptoms) through assessing pre- and post-surveys. The goals of this present study were to address the following research questions: (1) Will risk factors improve from pre- to post-survey? (2) Will significant relationships exist between eating disorder risk factors? (2) Will the intervention change the strength of the relationships between risk factors? (3) Does a participant's BMI change the effectiveness of the intervention? 


\section{Methodology}

\section{Participants}

The Body Project program was implemented by Illinois State University’s Student Counseling Services and Health Promotion and Wellness departments. Participation in the Body Project program was open to all women who attend the University. Illinois State University has a student population of about 18,000 undergraduate students (approximately 55\% female and 45\% male) and about 2,300 graduate students (58\% female and 42\% male) (Quick Facts about Illinois State, 2016). Minorities (American Indian, Alaskan Native, Asian, Black/African American, Hawaiian/Pacific Islander, and Hispanic) make up $22.3 \%$ of the undergraduate population and $26 \%$ of the graduate population ("Illinois State Student Enrollment Reports," 2014). Social media outlets were the most utilized recruitment tools. The University’s Student Counseling Services website and Twitter account were the most applied social media recruitment tools. University-wide emails was also utilized multiple times per year to promote the program. Promotional posters were distributed and displayed in educational and recreational facilities throughout the university's campus.

An online application process was utilized to allow easy and confidential access to the program. Three to six general implementations of the Body Project were available for individuals to register each semester over the two-year time-frame examined. In addition, groups of women such as women's organizations and sororities applied for body project sessions by completing an Outreach and Consultation form. Once an individual or group registered for the workshops, two

reminder emails were sent to email accounts by Student Counseling Services staff two weeks and one week before session dates, respectively. A minimum of four participants were required to register as part of a group in order for the workshop to be held. 


\section{Body Project Intervention}

The Body Project intervention was led by certified peer facilitators who attend Illinois State University. Each peer facilitator was required to participate in a two-day facilitator workshop led by university staff trained in implementing Body Projects workshops. Participants of the Body Project partook in either two 2-hour workshops or four 1-hour workshops where they used written, verbal, and behavioral exercises to critique the thin-ideal. Groups typically had anywhere from 3 to 10 participants per workshop and at least three peer facilitators. In sessions 1 and 2, participants defined the thin-ideal and discussed its origins, brainstormed various costs associated with pursuing the thin-ideal, participated in a verbal challenge exercise to practice positive responses to instances when someone felt pressured to conform to the thin-ideal, and challenged fat talk. Home activities for sessions 1 and 2 included coming up with one behavioral challenge to do before the next session that they currently did not do because of body image concerns, writing a letter to a young girl who be struggling with body-image while pursuing the thin-ideal, and completing a mirror exercise where participants who looked in the mirror and wrote down 15 positive qualities (includes physical, emotional, intellectual, and social qualities). In sessions 3 and 4, participants debriefed at home activities, role played to discourage pursuit of the thin-ideal, brainstormed body activism strategies by generating a list of things that girls and women can do as individuals to resist the thin-idea. They also identified and verbalized two body activism activities that each participant intended to do within the next week, identified future

pressures to be thin that could arise, and practiced quick comebacks to thin-ideal statements. Exit at home activities included participants verbalizing to the group which self-affirmation exercise they planned to do over the next week and writing a letter to another young girl. 


\section{Data Collection}

Prior to starting the workshop, an informed consent form was provided to participants which stated that participation was voluntary and confidentiality would be maintained in regards to any discussions during the workshop. Participants were also informed that the surveys may be analyzed for research purposes, but names would not be collected with the data in order to maintain anonymity. After each Body Project workshop, a trained individual employed through Student Counseling Services entered survey data into a password-secured database. Pre-surveys and post-surveys that were not filled out or only partially completed were not entered into the database. The Body Project participants' pre-survey and post-survey scores from September 2014- April 2016 at Illinois State University were analyzed to determine whether or not a change occurred in survey scores from pre-survey to post-survey and to determine if a relationship existed between BMI and survey scores.

\section{Measures}

The following risk factor categories were assessed in the surveys: (1) Ideal-thin internalization- assessed the extent to which a person acknowledges and believes in the ideals of attractiveness that are socially constructed and engages in behaviors in hopes of achieving these ideals (Thompson, et. al., 1999), (2) Dietary restraint- assessed attitudes towards food and intake patterns, (3) Body dissatisfaction- assessed contentment of body parts that are often of concern for females (i.e., stomach, thighs, hips), (4) Negative affect- assessed the extent to which participants felt negative emotions (i.e., anxious, depressed, lonely), (5) Eating disorder symptoms- assessed common symptoms of eating disorders (i.e., vomiting, use of laxatives, skipping meals), (6) BMI- self-reported current height and weight. 
Ideal-thin Internalization (Appendix, Part 1). Thin-ideal internalization was assessed using the Ideal-Body Stereotype Scale-Revised (Stice, E., Fisher, M., Martinez, E, 2004). The scale consisted of eight questions and responses ranged from $1=$ strongly disagree to $5=$ strongly agree. Scores were summed with a minimum possible score of eight and maximum possible score of 40 . Higher scores indicated the participant had a greater eating disorder risk factor. Internal consistency $(\alpha=.91)$, test-retest reliability $(\mathrm{r}=.80)$, and predictive validity for the onset of bulimic symptoms have been shown (Stice, Fisher, Martinez, 2004).

Diet Restraint (Appendix, Part 2) Frequency of dieting behaviors were assessed using the 10-item Dutch Restrained Eating Scale (van Strien, et. al., 1986). There were 10 questions with responses that ranged from $1=$ never to $5=$ always. Scores were summed and range from 10 to 50. Higher scores indicated the participant had a greater eating disorder risk factor. Internal consistency $(\alpha=.95)$ and 2-week test-retest reliability $(\mathrm{r}=.82)$ have been previously reported (Stice, Sysko, Roberto, \& Allison, 2010; Stice et al., 2006; van Strien 1986).

Body Dissatisfaction (Appendix, Part 3). Body dissatisfaction of nine body parts and body areas were assessed using the Satisfaction and Dissatisfaction with Body Parts Scale (Berscheid, Walster, \& Bohrnstedt, 1973). Responses ranged from $1=$ extremely dissatisfied to 5 $=$ extremely satisfied. Scores were summed and ranged from 9 to 45 . Higher scores indicated the participant had a lower eating disorder risk factor. Internal consistency $(\alpha=.94)$, test-retest reliability $(\mathrm{r}=.90)$, predictive validity for bulimic symptom onset, and sensitivity to detecting intervention effects have been previously reported (Stice et al., 2006).

Negative Affect (Appendix, Part 4). Twenty items from the Beck Depression Inventory (Beck, Steer, \& Carbin, 1988) assessed negative affect (the experience of negative emotions). Response options ranged from $1=$ not at all to $5=$ extremely. Scores were summed and range 
from 20 to 100 . Higher scores indicated the participant had a greater eating disorder risk factor. Internal consistency $(\alpha=.73-.95)$ and test-retest reliability $(r=.60-.90)$ have been shown and are valid comparable with ratings of clinical depressive symptoms (Beck, Steer, \& Carbin, 1988).

Eating Disorder Symptoms related to body image (Appendix, Part 5A \& B). A semistructured Eating Disorder Diagnostic Survey (EDDS) (Stice, Fisher, \& Martinez, 2004) assessed eating disorder symptoms as defined by the Diagnostic and Statistical Manual of Mental Disorders 4th edition (DSM-IV). The EDDS is a self-screening tool that has shown internal consistency $(\mathrm{a}=.89), 1$-week test-retest reliability $(\mathrm{r}=.87)$, and convergent validity (Stice, Fisher, \& Martinez, 2004; Stice, Telch, \& Rizvi, 2000). For the purpose of this study, this section was grouped into two parts. Part 1 consisted of four questions regarding feelings towards one's self and body image. Response options ranged from $0=$ extremely to $6=$ not at all. Scores were summed and ranged from 0 to 24 . Higher scores indicated the participant had a lower eating disorder risk factor. Part 2 consisted of 14 questions regarding a variety of questions related to symptoms of eating disorders such as binging symptoms, losing control while eating, feelings of guilt while eating or after eating, purging behaviors, etc. Response options were a combination of "yes" and "no" answers and answers indicating the number of days per week a person acted on eating disorder behaviors, if any.

$B M I$ (Appendix, Part 6). BMI is a weight-to-height index that is used to classify weight and estimate fat mass (Zuguo et al., 2002). Classifications are as follows: underweight is less than $18.5 \mathrm{~kg} / \mathrm{m}^{2}$, normal weight is 18.5 to $24.9 \mathrm{~kg} / \mathrm{m}^{2}$, overweight is 25 to $29.9 \mathrm{~kg} / \mathrm{m}^{2}$, class I obesity is $30-34.9 \mathrm{~kg} / \mathrm{m}^{2}$, class II obesity is 35 to $39.9 \mathrm{~kg} / \mathrm{m}^{2}$, and class III obesity is greater than or equal to $40 \mathrm{~kg} / \mathrm{m}^{2}$. Body mass index (BMI) was calculated by entering self-reported height and weight into the Standard BMI Calculation Tool, accessible on the National Heart, Lung, and 
Blood Institute webpage. BMI was then categorized into two groups, normal weight (BMI of 18.624.9) and overweight or obese (BMI $\geq 25$ ). Two questions regarding menstruation and birth control were included in the survey section but not analyzed in this study.

\section{Data Analysis}

In total, this study analyzed data from 51 women who participated in the Body Project workshops and completed the pre- and post-surveys. Partially completed surveys that had one section or more of the survey incomplete were not included in the analysis. Questions that were left blank (10 missing questions or less in total were included in analysis) were manually filled in by averaging the participant's questions in that risk factor section of the survey. Also, participants who did not attend the entire workshop (2, 2 hour sessions or 4, 1 hour sessions) were not included in the analysis. Pre- and post-surveys were assigned "Parts" (1-5E) for the purpose of this study in order to improve identification of measures.

Inferential statistics were utilized to determine the effect, if any, that the Body Project workshop had on survey scores. Data were collected and entered into Microsoft Excel. All analysis and interpretation of data were completed using Version 22 of SPSS, and the significance level was set at .05 with p-values falling below this threshold considered significant. Paired-samples t-tests were utilized to answer the first research question, "Will risk factors improve from pre- to post-survey?" To address research questions two and three, Pearson's Correlation was performed to determine whether significant relationships existed between eating disorder risk factors and if those relationships changed from pre- to post-survey. Analysis of covariance (ANCOVA) was utilized to address the fourth research question aimed to determine if differences exist in the effects of the intervention among individuals classified as either being a healthy weight or overweight/obese. Univariate analysis of variance was conducted to determine 
if a relationship existed between BMI and pre-survey score. Frequency analyses was utilized to examine the averages and frequencies of pre-survey results for eating disorder symptoms Parts B.

\section{Results}

\section{Descriptive Statistics}

Descriptive statistics uncovered trends in pre-survey results of eating disorder symptoms (part B). Thirty-five participants (31.4\%) indicated that there were times over the past month that they felt they had eaten what other people would regard as an unusually large amount of food (e.g., a quart of ice cream) given the circumstances. Eleven participants (21.6\%) experienced a loss of control during the times they ate an unusually large amount of food. The median BMI calculated for participants was 24.7 (healthy weight category) and the mean was 25.9 (overweight category). One participant (1.9\%) reported making herself vomit one time per week on average and using laxatives or diuretics one time per week on average over the past month to prevent weight gain or counteract the effects of eating. Twelve participants $(23.5 \%)$ reported fasting (skipping at least two meals in a row) an average of four times per week over the past month to prevent weight gain or counteract the effects of eating and fourteen participants (25.9\%) engaged in excessive exercise an average of four times per week over the past month specifically to counteract the effect of overeating episodes.

\section{Improvement of Risk Factors}

Paired-samples t-tests $(\mathrm{n}=51)$ were conducted to determine whether there was a statistically significant mean difference between pre-survey and post-survey results after participants participated in the Body Project program. Tables 1 and 2 provide individual statistics including means and standard deviations for pre- and post-survey results. Participants 
experienced statistically significant improvements in all five of the eating disorder risk factors measured after participating in the Body Project workshop. Thin-ideal Internalization (25.255 \pm 6.174 points $)$ experienced a statistically significant mean decrease of 7.275 points $(17.980 \pm$ $7.055, p<.001)$. Diet Restraint (28.588 \pm 8.830 points $)$ experienced a statistically significant mean decrease of 6.649 points $(21.400 \pm 8.888$ points $), p<.001)$. Negative Affect $(43.167 \pm$ 15.304) experienced a statistically significant mean decrease of 9.931 points $(33.235 \pm 13.997)$; , $p<.001)$. Body Dissatisfaction and eating disorder symptoms related to body image also showed significant improvements. Body dissatisfaction (24.490 \pm 7.829$)$ experienced a statistically significant mean increase of 6.649 points $(29.353 \pm 7.774, p<.001)$. Eating disorder symptoms related to body satisfaction $(10.451 \pm 7.106)$ experienced a statistically significant mean increase of 2.549 points $(13.000 \pm 7.017), p<.005)$.

Participants reported feeling more satisfied with their weight, figure, etc. (refer to postsurvey in Appendix A) after the workshop as results showed a mean decrease in body dissatisfaction of $6.649, p<.001$. Participants also reported improved eating disorder symptoms related to body image with results showing a mean decrease in feelings of disappointment in physical appearance of $2.549, p<.001$. Thin-ideal internalization had the greatest decrease of the eating disorder risk factors (22.7\% improvement), followed by dieting behaviors $(16.6 \%$ improvement), body dissatisfaction (13.5\% improvement), negative affect (12.4\% improvement), and eating disorder symptoms (7.1\% improvement).

\section{Relationships Between Risk Factors}

Pearson's correlations revealed significant positive correlations between eating disorder measures in both the pre-survey and post-survey results. There were also changes in correlations between measures from pre- to post-survey results (see Table 3 and 4). Pre-test results revealed 
that higher levels of body dissatisfaction were strongly correlated to greater eating disorder symptoms related to body image $(r=.781, p<.001)$. Higher levels of dieting behaviors were also strongly related to poor body satisfaction $(r=-.517, \mathrm{p}=.001)$ and more eating disorder symptoms related to body image $(r=.600, p<.001)$. Data analysis also revealed that higher levels of negative affect were moderately correlated to more eating disorder symptoms related to body image $(r=-.479, p<.001)$ and body dissatisfaction $(r=-.475, p<.001)$. Therefore, people who reported greater feelings of negative affect also reported lower levels of body satisfaction and greater more eating disorder symptoms related to body image.

Post-test results revealed that dieting behaviors were moderately negatively correlated to eating disorder symptoms related to body image $(r=-.495, p<.001)$, body dissatisfaction $(r=$ $.486, p<.001)$, and negative affect $(r=.495, p<.001)$. Therefore, participants who reported lower frequency of dieting behaviors also reported better body satisfaction, less eating disorder symptoms related to body image, and less feelings of negative emotions. Eating disorder symptoms related to body image were strongly positively correlated with body dissatisfaction $(r$ $=.597, p<.001)$, indicating that participants who had fewer eating disorder symptoms also experienced improved body satisfaction.

\section{Body Mass Index}

BMI was calculated based on participants' self-reported height and weight. The sample had a mean BMI of $25.9(\mathrm{SD}=6.6)$. A one-way analysis of covariance (ANCOVA) was conducted to determine if a statistically significant difference existed between pre-survey and post-survey results controlling for BMI (refer to Table 4 in Appendix). Results showed that there was no significant effect on ideal-thin internalization, diet restraint, or negative affect post completion of the Body Project workshop after controlling for BMI. However, there was a 
significant difference in body dissatisfaction when controlling for $\mathrm{BMI}(\mathrm{F}=4.54, p<.05)$.

Bonferroni post-hoc analyses were performed to determine which BMI group category scored significantly different when comparing pre- and post-survey results. Results showed that body dissatisfaction was significantly improved in participants with higher BMIs (overweight/obese) compared to participants with lower BMIs (normal), a mean difference of 3.692 points, $p<.05$.

\section{Discussion}

\section{Intervention Effects}

Ideal-thin internalization showed improvement at post-test, which is consistent with previous studies that measured Body Project effects. It is important to note that this dissonancebased eating disorder prevention program is built around the foundation of critiquing the thinideal, which in theory produces cognitive dissonance and helps participants decrease their internalization of the thin-ideal. Stice and Rohde (2011) found that when controlling for thinideal internalization, the intervention effects on the other four risk factors became significantly weaker. The Peer-Leader Body Project Script that facilitators use to guide the sessions had the facilitators list six main goals that are expected to be accomplished at the end of the workshops, which included defining the thin-ideal and exploring its origin, examining the costs of pursuing this thin-ideal, exploring ways to resist pressures to be thin, discussing how to challenge out personal body-related concerns, learning new ways to talk more positively about their bodies, and talking about how one can best respond to future pressures to be thin. Post-survey questions aimed to measure the success of change that resulted from those concepts, but all concepts were approached taking into consideration how they relate to ideal-thin internalization. To address the research question, all eating disorder risk factors improved from pre- to post-survey. Improvements of dieting behaviors, body satisfaction, negative affect, and eating disorder 
symptoms related to body image are also highly supported in the literature (Stice \& Butryn, 2013; Stice \& Rohde, 2013; Stice \& Rohde, 2011; Stice \& Marti, 2011; Stice \& Presnell, 2007; Stice \& Shaw, 2006).

A deviation found in the study was the intervention effect on negative affect. It was expected that negative affect would show greater improvements than the study produced, as the literature has shown strong relationships between depression and susceptibility to developing an eating disorder (Evans et al., 2016; Keel et al., 2000; Wolfe \& Hewitt, 2016; Manaf, 2016). Existing literature on the Body Project produced mixed results with intervention effects on negative affect (Stice et al., 2012; Stice et al 2008). There is a complex phenomenon of increased risk for comorbidities in people who exemplify eating disorder risk factors. The interrelationship of these disorders make research on these factors of upmost importance in order to identify best practice for eating disorder prevention programs.

\section{Correlations Between Risk Factors}

The majority of results from the current study looking at correlations between risk factors were congruent with the Dual Pathway Model (1994). The intervention of the current study changed the strength of the relationships between eating disorder risk factors from pre- to postsurvey. Body dissatisfaction and eating disorder symptoms related to body image were strongly correlated in pre-survey scores but were only moderately correlated after the intervention. Similarly, dieting behaviors and body dissatisfaction had significant pre-survey correlations but only moderate post-survey correlations. Body dissatisfaction went from being strongly correlated in pre-surveys to moderately correlated in post-surveys to eating disorder symptoms related to body image. There were three correlations that existed between pre-survey risk factors but not post-survey factors; dieting behaviors and eating disorder symptoms, negative affect and eating 
disorder symptoms, and negative affect and body dissatisfaction. One new relationship emerged between risk factors in post-test correlations between dieting behaviors and negative affect.

Based on Stice's Dual Pathway Model, it was expected that thin-ideal internalization would be strongly correlated to body dissatisfaction in both pre-survey and post-survey scores. It was an unexpected finding that although significant pre-survey correlations were present in three of the four risk factors and post-survey correlations were present in two of the four risk factors, correlations were weak to moderate (Pre-survey: $\mathrm{r}=.341, \mathrm{r}=-.299, \mathrm{r}=-.410$; Post-survey: .339, .352). This could suggest that the Body Project is less effective when implemented in real-world settings compared to the theoretical model.

The strongest significant pre-survey correlation was between body dissatisfaction and eating disorder symptoms related to body image. This is highly expected as both relate to how one feels about his/her body. The strength of the relationships would have likely differed if correlations were tested for all eating disorder symptoms rather than only those related to body image. Again referring to assumptions from the Dual-Pathway Model, increased feelings of body dissatisfaction were expected to be correlated to more dieting behaviors and worsened negative affect. Pre-survey results found that participants with poorer body dissatisfaction also showed this relationship between body dissatisfaction and dieting behaviors. there was a slightly stronger correlation to dieting behaviors than negative affect $(\mathrm{r}=-.517, \mathrm{p}<.001$ vs $\mathrm{r}=-.475$, $\mathrm{p}<.001)$. Post-intervention correlations were weaker, but similar to pre-intervention correlations. This finding is consistent with Stice's $(2000,2001)$ studies that tested the Dual-Pathway Model of bulimic pathology in that while both were correlated to body dissatisfaction, more dieting behaviors had a stronger correlation than increased feelings negative affect. Dieting is thought to predict more feelings of negative affect due to feelings of failure that are associated with weight 
control efforts and due to the physiological effect that calorie deprivation has on mood (Stice, 2001).

Post-survey results showed weaker correlations between factors across the board compared to pre-survey results. Each individual who participated in the Body Project experienced the intervention in their own way, which likely accounted for the greater variability of responses and decrease in correlation strength. Each measure has the ability to change differently and at different rates.

Stice's Dual-Pathway model for bulimic pathology contributed to the literature by producing a solid theoretical framework for conceptualizing the interrelationship between eating disorder risk factors. Since this model was published, it has been frequently referenced by other eating disorder researchers and new versions of this model have been explored. Findings from the current research study will positively contribute to this literature and has the potential to be used for future modifications or additions of theoretical components that contribute to bulimic symptoms.

\section{Body Mass Index}

BMI data was originally sorted into three categories; normal weight, overweight, and obese. Grouping within these parameters decreased testing reliability because group sizes were very uneven. Grouping was changed to just two categories, normal weight or overweight and obese (I-III), which improved category balance. Twenty-one participant's BMIs were in the normal range and twenty-two were overweight or obese (class I-III). Mean body mass index calculated from pre-survey reports was $25.9 \mathrm{~kg} / \mathrm{m}^{2}$. Most studies that examined how BMI related to eating disorder prevention strategies in college-aged women had significantly lower mean BMI means prior to the intervention compared to the current study (Argyrides \& Kkeli, 2014; 
Stice et al., 2011; Stice et al., 2007). The reason for this difference is unclear. Obesity is highly associated with risk factors of bulimia and disordered eating behaviors. Greater BMI in the test population may suggest that the participants were very appropriate for the Body Project intervention because, in theory, increased BMI coupled with thin-ideal internalization leads to body dissatisfaction, a known risk factor for the development of binge eating disorder.

ANCOVA and post-hoc analyses revealed that body dissatisfaction was significantly improved in participants with higher BMIs compared to participants with lower BMIs. This outcome supports BMI as a predictor of body satisfaction (Jones, 2004). Pre-survey and postsurvey score changes did not differ between BMI groups in four of the five eating disorder risk factors measured.

\section{Limitations}

It is important to consider limitations of the current study when interpreting the results. Pre- and post-survey data was analyzed from Body Project implementations conducted in past years. Consequently, we were not able to collect demographic data and other personal descriptors due to limitations placed by the IRB prior to this study. Because it is well accepted that adolescent women are the population at greatest risk for development of eating disorder, this study along with a majority of existing literature focus on adolescent women and excludes various populations of people that have eating disorders. Eating disorders are not limited to occur in one gender, ethnicity, or socioeconomic class. This gap in the literature needs to be further explored in order to tailor intervention strategies to benefit all populations that are effected with eating disorders.

The current evidence is mixed if these eating disorder programs also decrease participant's likelihood of experiencing unhealthy weight gain at post-tests and long-term 
follow-up testing. Due to limited resources, this study did not evaluate the long-term intervention effects on BMI. Continued exploration of BMI trends and the mediation effects that BMI could have on decreasing risk factors is crucial for improving health outcomes. For BMI and examining the relationships between survey questions, mediation was not tested, but rather relationships were examined with ANCOVA, post-hoc tests, and Pearson's Correlation. Testing for mediation rather than correlation would have improved outcome reliability and allow the independent variable to predict change in the mediator.

This study's relatively small sample size should also be noted. Furthermore, there were 14 missing pre- and post-test values combined from pre-and-post surveys. These missing values were replaced by using the average of the survey section responses in place of the missing value. In total, there were twelve missing values that were replaced with section averages.

\section{Conclusion}

Findings of this study add to the existing body of literature that examines the effectiveness of the Body Project and similar dissonance-based eating disorder prevention programs. Efficacy trials of eating disorder prevention programs are important because they examine if desired outcomes from the program can be successfully reproduced by various trained providers. Evidence from this efficacy study suggests that the personnel at Illinois State University who were trained on implementing this program were successful at appropriately training peer facilitators and implementing the workshops. Baseline data and the improvement of all eating disorder risk factors post-intervention suggests that the population that participated in the Body Project were a very appropriate group for the intervention. This shows that Illinois State's methods for promoting the Body Project are appropriate and are reaching populations that are at risk for experiencing body image concerns. 
Results from the one-way analysis of covariance (ANCOVA) should be explored further. The Body Project was more effective at improving body dissatisfaction in participants with BMIs greater than $25 \mathrm{~kg} / \mathrm{m}^{2}$. Although exploring if BMI would mediate outcomes for certain eating disorder risk factors would have allowed stronger inferences to be made, this correlation data brings insight into the importance of researching more into the role that BMI has in eating disorder risk factor pathology. Furthermore, continuing exploration into the incorporation of components utilized in other eating disorder prevention programs that put an emphasis on maintaining a healthy weight could improve the Body Project's outcomes for decreasing unhealthy weight gain at long-term follow-ups. Patterns in the literature suggest that dissonance interventions are inferior at producing weight gain prevention effects compared to the healthy weight interventions but superior at reducing eating disorder risk factors (Stice, et al., 2006; Stice et al., 2007; Stice et al., 2008; McMillan, Stice, \& Rohde, 2011).

All published effectiveness and efficacy trials conducted on the Body Project by Stice utilized screening tools to identify existing eating disorders in women who were interested in the Body Project and to exclude that population from the program, as the program's purpose is to help prevent eating disorders rather than treat existing conditions. Illinois State does not currently use any such screening tool, and it is important to consider the potential consequences that could occur from having participants in the body project who currently have eating disorders. These participants may not be able to fully challenge the thin-ideal, and the Body Project is not meant to be an eating disorder treatment program. It would be interesting to see the effects that a participant with an eating disorder would have on their peers. Would cognitive dissonance decrease if the participant was verbally going against challenging the thin-ideal? An initial screening tool was utilized in most of the previous Body Project efficacy trials to identify 
participants who met the criteria for DSM-IV anorexia nervosa, bulimia nervosa, or binge eating disorder (Stice et al., 2006; Stice et al., 2009; Stice et al., 2011; Stice et al., 2013). Those participants were then excluded from the study, strongly encouraged to seek treatment, and provided with resources. Having participants at Illinois State and other satellite Body Project programs include a similar screening tools could potentially lead to improved outcomes.

\section{Future Directions}

Although there is a strong evidence base for this eating disorder prevention program, findings could lead to intervention refinement. Continued research needs to be done to further unravel the complex relationship between eating disorder risk factors and methods for reducing the prevalence of all eating disorders. Most literature that examines dissonance-based eating disorder prevention programs have utilized the population of female college students. There is still much research to be conducted on how dissonance-based interventions eating disorder programs can benefit different genders and age groups.

Dissonance-based interventions have been utilized in many professions to produce behavior change, including nutrition and dietetics (Schumacher \& Slep, 2004; Axsom \& Cooper, 1981). However, current educational textbooks often focus on other psychology frameworks from the Social Cognitive Theory and Cognitive Behavioral Therapy (Murphy et at., 2010). Continued research into the role that cognitive dissonance could have in eating disorder prevention and treatment could lead to improved practices and outcomes of health professionals within multidisciplinary eating disorder treatment teams. 


\section{References}

About Illinois State University. Quick facts about Illinois State. Illinois State University Website. https://illinoisstate.edu/quickfacts/. Accessed January 2017.

Arcelus, J., Mitchell, A. J., Wales, J., \& Nielsen, S. (2011). Mortality rates in patient with anorexia nervosa and other eating disorders. Archives of General Psychiatry, 68(7), 724731.

Beck, A. T., Steer, R. A., \& Carbin, A. G. (1988). Psychometric properties of the Beck Depression Inventory: Twenty-five years later. Clinical Psychology Review, 8(1), 77-100.

Berscheid, E., Walster, E., \& Bohrnstedt, G. (1973). The Happy American Boy: A survey report. Psychology Today, 7,119-131.

Gartlehner G., Hansen R A., \& Nissman, D. (2006). Criteria for distinguishing effectiveness from efficacy trials in systematic reviews: Agency for healthcare research and quality. Technical Reviews, 12.https://www.ncbi.nlm.nih.gov/books/NBK44024/.

Henderson, C., Evans-Lacko, S., \& Thornicoft, G. (2012). Mental illness stigma, help seeking, and public health programs. American Journal of Public Health, 103(5), 777-780.

Hendrick, A., \& Burgoon, M. (2003). The relationship between fashion magazine consumption and body satisfaction in women: Who is most at risk of influence? American Communication Journal, 14(2), 41-57.

Hoerr, S. L., Bokram, R., Lugo, B., Bivins, T., \& Keast, D. R. (2002). Risk for disordered eating related to both gender and ethnicity for college students. Journal of American College Nutrition, 21(4), 307-314.

Jones, M., Kass, A. W., Trockel, M., Glass, A. I., Wilfley, D. E., \& Taylor, B. C. (2014). A population-wide screening and tailored intervention platform for eating disorders on 
college campuses: The healthy body image program. Journal of American College Health, 62(5), 351-356.

National Eating Disorder Association. What are eating disorders? National Eating Disorder Association website. https://www.nationaleatingdisorders.org/get-facts-eating-disorders. Accessed June 2016.

National Institute of Mental Health. Eating disorders: risk factors. National Institute of Mental Health website. https://www.nimh.nih.gov/health/topics/eating-disorders/index.shtml. Accessed June 2016.

Planning, Research, and Policy Analysis: On-Campus Enrollment Reports 2014. Illinois State StudentReports.http://prpa.illinoisstate.edu/data_center/student/enrollment.shtml. Retrieved January 2017.

Smink, F. E., van Hoeken, D., \& Hoek, H. W. (2012). Epidemiology of eating disorders: Incidence, prevalence, and mortality rates. Current Psychiatry Reports, 14(4), 406-414.

Stice, E., Fisher, M., \& Martinez, E. (2011). Eating disorder diagnostic scale: Additional evidence of reliability and validity. Psychological Assessment, 16, 60-71.

Stice, E., Fisher, M., Sysko, R., Roberto, C. A., \& Allison, S. (2010). Are dietary restraint scales valid measures of dietary restriction? Addition objective behavioral and biological data suggests not. Appetite, 52(2), 331-339.

Stice, E., Telch, C. F., \& Rizvi, S. L. (2000). Development and validation of the eating disorder diagnostic scale: A breif self-report measure of anorexia, bulimia, and binge-eating disorder. Psychological Assessment, 12(2), 123-131. 
van Strien, T., Frijters, J. E., van Staveren, W. A., Defares, P. B., \& Deurenberg, P. (1986). The predictive validity of the Dutch Restrained Eating Scale. International Journal of Eating Disorders, 5, 747-755.

Walsworth, K. P., Perkins, G. W. A population at risk: College-aged females and eating disorders. American Counseling Association. VISTAS Online, Article 25. Accessed January 2017.

Zugeo, M., Grummer-Strawn, L. M., Pietrobelli, A., Goulding, A., Gordan, M. I., \& Dietz, W. H. (2002). Validity of body mass index compared with other body-composition screening indexes for the assessment of body fatness in children and adolescents. American Society for Clinical Nutrition, 75, 978-85. 


\section{Tables}

Table 1.

Paired Sample $t$-tests Comparing Eating Disorder Risk Factor Differences from Preto-Post Survey

\begin{tabular}{|c|r|r|r|r|r|}
\hline Measures & $\begin{array}{c}\text { Pre-survey } \\
\text { Mean }\end{array}$ & $\begin{array}{c}\text { Post-Survey } \\
\text { Mean }\end{array}$ & \multicolumn{1}{c|}{$t$} & St. Dev. & $\begin{array}{c}\text { Sig. } \\
\text { (2-tailed) }\end{array}$ \\
\hline $\begin{array}{c}\text { Ideal-thin } \\
\text { Internalization }\end{array}$ & 25.25 & 17.98 & $7.27^{* *}$ & 6.48 & $<.001$ \\
\hline Diet Restraint & 28.59 & 21.94 & $6.65^{* *}$ & 7.39 & $<.001$ \\
\hline $\begin{array}{c}\text { Body } \\
\text { Dissatisfaction }\end{array}$ & 24.49 & 29.35 & $-4.86^{* *}$ & 7.01 & $<.001$ \\
\hline $\begin{array}{c}\text { Negative Affect } \\
\text { Eating Disorder }\end{array}$ & 43.17 & 33.34 & $9.93^{* *}$ & 11.59 & $<.001$ \\
\hline Symptoms :Part A & 10.45 & 13.00 & $-2.55^{*}$ & 7.20 & .015 \\
\hline
\end{tabular}

$*=t$-test is significant at the .05 level

$* *=t$-test is significant at the .01 level

Table 2.

Pearson's Correlation Pre-Survey Results

\begin{tabular}{|c|c|c|c|c|c|}
\hline Measures & $\begin{array}{c}\text { Ideal-thin } \\
\text { Internalization }\end{array}$ & $\begin{array}{c}\text { Diet } \\
\text { Restraint }\end{array}$ & $\begin{array}{c}\text { Body } \\
\text { Dissatisfaction }\end{array}$ & $\begin{array}{c}\text { Negative } \\
\text { Affect }\end{array}$ & $\begin{array}{c}\text { Eating Disorder } \\
\text { Symptoms }\end{array}$ \\
\hline $\begin{array}{c}\text { Ideal-thin } \\
\text { Internalization }\end{array}$ & 1 & $r=.250$ & $r=-.410^{* *}$ & $r=.341^{*}$ & $r=-.299^{*}$ \\
\hline Diet Restraint & $r=.250$ & 1 & $r=-.517^{* *}$ & $r=.431^{* *}$ & $\mathrm{r}=-.600^{* *}$ \\
\hline $\begin{array}{c}\text { Body } \\
\text { Dissatisfaction }\end{array}$ & $r=-.410^{*}$ & $r=-.517^{* *}$ & 1 & $r=-.475^{* *}$ & $r=.781^{* *}$ \\
\hline $\begin{array}{c}\text { Negative Affect } \\
\text { Eating Disorder } \\
\text { Symptoms :Part A }\end{array}$ & $r=.341^{*}$ & $r=.431^{*}$ & $r=-.475^{* *}$ & 1 & $r=-.479^{* *}$ \\
\hline
\end{tabular}

$*=$ significant at the .05 level

$* *=$ significant at the .01 level 
Table 3.

Pearson's Correlation Post-Survey Results

\begin{tabular}{|c|c|c|c|c|c|}
\hline Measures & $\begin{array}{c}\text { Ideal-thin } \\
\text { Internalization }\end{array}$ & $\begin{array}{c}\text { Diet } \\
\text { Restraint } \\
\text { Dissatisfaction }\end{array}$ & $\begin{array}{c}\text { Negative } \\
\text { Affect }\end{array}$ & $\begin{array}{c}\text { Eating } \\
\text { Disorder } \\
\text { Symptoms }\end{array}$ \\
\hline $\begin{array}{c}\text { Ideal-thin } \\
\text { Internalization }\end{array}$ & 1 & $\mathrm{r}=.339^{*}$ & $\mathrm{r}=-.352^{*}$ & $\mathrm{r}=.249$ & $\mathrm{r}=-.227$ \\
\hline Diet Restraint & $\mathrm{r}=.339^{*}$ & 1 & $\mathrm{r}=-.486^{* *}$ & $\mathrm{r}=.452^{* *}$ & $\mathrm{r}=-.495^{* *}$ \\
\hline $\begin{array}{c}\text { Body } \\
\text { Dissatisfaction }\end{array}$ & $\mathrm{r}=-.352^{*}$ & $\mathrm{r}=-.486^{* *}$ & 1 & $\mathrm{r}=-.387^{*}$ & $\mathrm{r}=.597^{* *}$ \\
\hline $\begin{array}{c}\text { Negative Affect } \\
\text { Eating Disorder } \\
\text { Symptoms :Part A }\end{array}$ & $\mathrm{r}=.249$ & $\mathrm{r}=.452^{* *}$ & $\mathrm{r}=-.387^{*}$ & 1 & $\mathrm{r}=-.262$ \\
\hline
\end{tabular}

$*=$ significant at the .05 level

$* *=$ significant at the .01 level

Table 4.

BMI ANCOVA Results

\begin{tabular}{|c|c|c|}
\hline Measures & $f$ & $d f$ \\
\hline Thin-ideal Internalization & .549 & 1 \\
\hline Diet Restraint & .976 & 1 \\
\hline Body Dissatisfaction & $4.544^{*}$ & 1 \\
\hline Negative Affect & .807 & 1 \\
\hline Eating Disorder Symptoms: Part A & .710 & 1 \\
\hline
\end{tabular}

$*=$ significant at the .05 level 


\section{CHAPTER II}

\section{EXTENDED LITERATURE REVIEW}

\section{Eating Disorder Prevalence}

Disordered eating and eating disorders are complex in their origin and involve aspects of human nutrition as well as mental health. In addition to the contribution of cultural pressures to achieve thinness can have on the development of disordered eating, psychological, environmental, and genetic factors all contribute to the causes of eating disorders (NEDA). Anorexia, bulimia, and binge eating disorder are the three most common clinically diagnosed eating disorders in America with research showing that over 20 million women and 10 million men have suffered from a clinically significant eating disorder at some point in their lives (Archelus, et al., 2011). Evidence shows that people who are going through transitional periods in life have increased risk for the onset of an eating disorder (NEDA; Berge et al., 2011). It is not surprising that college-aged females have been identified as one of the greatest at-risk populations (Archelus, et al., 2011), heightening the importance of mental health resource availability at universities. A study that examined onset and changes of patterns of overeating and binge eating in adolescents indicated that symptoms of binge eating and binge eating disorder developed and/or worsened during the transition from late adolescents/early adulthood to early/middle adulthood (Goldschmidt et al., 2016). Additionally, depressive symptoms, body satisfaction, and self-esteem in late adolescent/early adulthood predicted the onset and/or worsening of binge eating in early/middle adulthood. This evidence reaffirms the serious risk adolescent women face for developing binge eating disorder behaviors, especially during the college years due to the life transitions. College women are a highly appropriate population to target for eating disorder risk factor assessment and prevention. 
Bulimia nervosa is an eating disorder that is characterized by compulsive overeating followed by methods of purging to avoid weight gain, which include self-induced vomiting, fasting, excessive use of laxatives or diuretics, and excessive exercise (National Eating Disorder Collaboration). High comorbidities of depression, anxiety, and substance abuse are often present creating treatment for recovery to require a multidisciplinary team of professionals (Academy for Eating Disorders). Even with appropriate treatment, statistics show that only $60 \%$ of people with eating disorders recover (Anorexia Nervosa and Related Eating Disorders). In a recent study that investigated brain alterations in women with bulimia nervosa, findings suggested that women with bulimia nervosa had significantly increased engagement of a section of the brain that indicates exacerbated self-focus while relating themselves to a thin-ideal cue compared to the healthy control subjects and caused an increase in self-reported levels of anxiety (Frederique et al., 2013). MRIs indicated that the women with bulimia nervosa did not engage that same part of the brain when exposed to food cues. Interestingly, healthy control women's MRIs showed no differences in brain responses when exposed to the thin-ideal verses the food cue. This evidence suggests that women with bulimia may receive great benefits from an eating disorder treatment approach that focuses on psychological challenges. However, nutrition professionals still play a crucial role on interdisciplinary treatment teams of eating disorder specialists. They reinforce positive food related behaviors, help the patient achieve behavior modifications around unhealthy food practices, and provide continual support.

\section{Eating Disorder Prevention Strategies}

Treatment for eating disorders is multifactorial and is best approached with a multidisciplinary team of specialists, as eating disorders are complex in nature. An eating disorder treatment team usually consists of 3-4 health professionals that each play a role in 
helping patients recover physically and psychologically. Even with an intense support system and professional help, most people that develop eating disorders never fully recover (NEDA, 2017). Though much research has been invested in examining the best practices for health professionals to treat eating disorders, strategies to reduce their occurrence have been less examined. Eating disorder prevention programs have been found to be extremely effective tools for various populations though there is currently no universal consensus on which type of eating disorder prevention strategy is most effective. Current strategies include incorporating parents into eating disorder prevention for their children (Hart et al., 2015), mindfulness-based interventions (Atkinson \& Wade, 2015), and psychoeducational approaches. Currently, a large proportion of eating disorder prevention programs are developed specifically for adolescent girls and women. Research suggests that two eating disorder prevention methods have shown themselves to be superior in improving risk factors for bulimia eating disorder and preventing future onset in this specific population. The healthy weight intervention strategy and the dissonance-based intervention strategies have set themselves apart in this area of research through replication of positive outcomes by independent labs (Becker et al., 2006; Michell et al., 2007; Matusek et al., 2004; Stice et al., 2006).

\section{Healthy Weight Interventions}

Healthy weight interventions have produced significant improvements in eating disorder risk factors. These interventions focus on encouraging lifestyle changes such as making healthy changes to dietary intake and increasing physical activity. Driven by theory, improvements in these areas should hypothetically promote body satisfaction, negative affect, and decrease the risk for unhealthy weight control behaviors (Stice et al., 2007; Klem, Wing, Simkin-Silverman, \& Kuller, 1997). Initially Stice and his team considered the healthy weight intervention approach 
to be a placebo control group in their studies but after researching emerging literature and producing similar outcomes to dissonance intervention studies, they concluded that the evidence supported the healthy weight intervention as a credible alternative strategy to decrease eating disorder symptoms (Stice \& Shaw, 2004; Matusek et al., 2004; Stice et al. 2003; Stice et al., 2008).

More recent studies found that healthy weight intervention efficacy and effectiveness trials generally show superiority compared to dissonance-based interventions in decreasing body mass index and preventing unhealthy weight gain, though trials show little effects on depressive symptoms at long-term (greater than 1 month) follow-up evaluations (Stice et al., 2008; McMillan, Stice, \& Rohde, 2011; Stice et al., 2012). A study conducted by Stice, Tros, and Chase (2003) that compared the intervention effects of the two programs suggested that both produced reductions in all eating disorder risk factors. However, the effects of the healthy weight intervention are typically not as strong as those produced by the dissonance program in most areas, except for reductions of body mass index (Stice, Trost, \& Chase, 2003).

Stice et al (2008) found that healthy weight intervention participants experienced greater reductions in bulimic eating pathology and risk for obesity onset compared to dissonance participants through a three-year follow-up. Stice (2012) later developed and tested intervention effects of a combined program that incorporated components from both eating disorder prevention approaches. Eating disorder symptoms, dieting, and body dissatisfaction were significantly lower at posttest than controls but these decreases did not last at 6-month follow-up. They also found that although there were no significant changes in BMI at posttest, participants at 1 standard deviation above the mean in pre-test eating disorder symptoms showed a significant and long-lasting decrease in BMI. This suggests that continued research into which healthy 
weight intervention components mediate the effects of bulimic eating pathology and risk for obesity onset could lay the groundwork for incorporating the components into dissonance-based programs to develop improved eating disorder prevention program.

\section{Dissonance Interventions}

Cognitive dissonance is a term used to describe the feelings of discomfort (dissonance) that results from having two conflicting thoughts, beliefs, or attitudes, especially when the conflict involves beliefs about behaviors or changes in attitude (Festinger, 1964). This theory is based off the principal of cognitive consistency, which states that people seek consistency between their own beliefs, attitudes, and actions. When dissonance increases from conflicting or inconsistent ideas, people are motivated to decrease their dissonance by either changing their beliefs, actions, or perceptions of their action to regain internal consistency. Making these changes will bring their dissonance back down and thoughts, beliefs, and actions regain congruency. Cognitive dissonance theory is often utilized in the field of social psychology and has been found to be beneficial in changing negative behaviors (McKimmie et al., 2015). Research has shown that health professionals can benefit from using principles of cognitive dissonance to facilitate positive behavior change in one-on-one consultation therapy and group therapy (Hughes, 1983; Bryant et al., 2000; McKimmie et al., 2015). Positive outcomes in the literature that explores different areas where cognitive dissonance can be utilized have laid a path for continued research and application of the theory.

Dissonance-based eating disorder risk factor prevention interventions utilize three fundamental assumptions from the cognitive dissonance theory; (a) humans are sensitive to inconsistencies between actions and beliefs; (b) recognition of this inconsistency will cause dissonance and will then motivate the individual to resolve these feelings; and (c) dissonance 
will be resolved by either changing beliefs, actions, or the perception of an action (Festinger \& Carlsmith, 1959). The duel pathway model of bulimic pathology demonstrates the theoretical components that lead to bulimic pathology utilized to develop the Body Project (Stice, 2001).

Thompson et. al. (1999) previously produced a pathway model for predictive relationships amongst risk factors for bulimia onset. The study found that negative affect may be the initial issue present that triggers body dissatisfaction and dieting, which in turn promotes bulimic pathology. Stice et al.'s study (2004) that was conducted to test the proposed Dual Pathway model also tested Thompson et al.'s (1999) theory. Stice et al's study (2004) addressed a previous limitation by controlling for baseline levels of bulimic symptoms. Results showed significantly weaker relationships between risk factors compared to the original study once baseline symptoms were taken into account. Stice et al. (2004) also examined growth in body mass at two-year follow-up to baseline levels of bulimic symptoms to ensure that the Dual Pathway Model explained bulimic symptoms rather than weight gain, as both have similar risk factors. Initial dieting predicted growth in body mass but no other risk factors significantly predicted that outcome, providing substantial evidence that the Dual Pathway Model led to appropriate predictive outcomes of symptoms of bulimia. Using this Model of Bulimic Pathology, the Body Project intervention was designed to reduce ideal-thin internalization and result in subsequent decreases in eating disorder risk factors (body dissatisfaction, dieting, negative affect, and bulimic eating disorder symptoms).

The Body Project dissonance-based intervention focuses on critiquing the thin-ideal and therefore theoretically reduces thin-ideal internalization, or the degree to which an individual internalizes the thin standard of feminine beauty in American culture, and other eating disorder risk factors. Thin-ideal internalization is a known risk factor for developing eating disorders 
(Argyrides \& Kkeli, 2014). A study that aimed to examine relationships and predictors between eating disorder risk factors utilized the EAT-26 instrument to identify symptoms of eating disorders. They found that increased disordered eating was significantly positively related to increased thin-ideal internalization, body image investment, weight-related anxiety, and BMI. Furthermore, disordered eating attitudes and behaviors were predicted by greater thin-ideal internalization.

McMillian, Stice, \& Rohde (2011) examined the effects that high and low level dissonance-based eating disorder prevention programs had on college students with body image concerns. They found that both conditions showed significantly greater reductions in ideal-thin internalization, body dissatisfaction, dieting, and eating disorder symptoms by post-test when compared to the waitlist control. Though evidence was minimal for the high-dissonance program outperforming the low-dissonance program, the researchers hypothesized greater pre-to-post-test effects from the high-dissonance program. Minimal changes in thin-ideal internalization was not expected because the greater dissonance program should have produced greater reductions in thin-ideal internalization (and subsequently the other risk factors) due to increased cognitive dissonance. It was concluded that results were (in part) due to intervention content rather than dissonance level. An objective that was found to concur with the original hypothesis was greater pre-to-post effect sizes in the high-dissonance intervention, suggesting greater high-dissonance intervention effectiveness.

Another unique component of the Body Project is the utilization of peer facilitators to lead the dissonance-based eating disorder prevention groups. The most common method for implementing eating disorder prevention programs in the past was using educational video/brochures or health professionals that would lead group sessions (Stice et al., 2009). 
Prevention programs facilitated by health professionals proved to be superior in reducing short and long-term risk factors but also create barriers for implementing programs (Stice et al., 2009). Limited availability of resources caused barriers for implementing programs in real-world settings. Few clinicians would be likely to volunteer extra time into implementing eating disorder prevention programs without compensation. Stice et al (2013) found that to be a major barrier, along with high clinician turnover rates at universities. Peer-leader health education and prevention programs are common at the university level (Hong et al., 2011). A peer lead dissonance-based eating disorder prevention program that was adapted for members of sororities showed that all eating disorder risk factors decreased at posttest when implemented by peers of the same sorority (Becker et al., 2010). Stice et al (2013) used this finding as a basis for developing a randomized control trial that further examined the phenomenon. Clinicians and peer leaders received the same facilitator training to implement the intervention. When compared to the control that read educational brochures on eating disorder prevention, both produced significant reductions in all eating disorder risk factors. However, clinician lead groups produced much greater posttest and 1-year follow-up improvements compared to peer-lead groups. This study also revealed that peer-lead groups had lower attendance and competence ratings (Stice et al, 2013). It is not surprising that clinician-lead groups produced superior outcomes, as they have vastly more training and experience. Due to limited clinician availability for facilitating Body Project workshops, continued refinement of the Body Project script and training approaches is needed to improve the efficacy of peer-lead programs. 


\section{Effect On BMI}

The current evidence is mixed as to which eating disorder programs, dissonance-based or healthy weight, also decrease participant's likelihood of experiencing unhealthy weight gain at post-tests and long-term follow-up testing. This is important to consider because unhealthy weight gain may lead to obesity which is associated with increased risks for developing comorbidities such as diabetes, cancer, heart disease, depression, and more. Obesity is not considered a mental disorder in the Diagnostic and Statistical Manual of Mental Disorders (DSM-5) and is not included in DSM-5 diagnostic criteria for any eating disorders. However, obesity is highly associated with a number of mental disorders including binge-eating disorder and depressive disorder (American Psychiatric Association; White \& Grilo, 2013).

Stice, Rohde, Shaw, and Marti conduced an efficacy trial for a prevention program that targeted both eating disorder symptoms and unhealthy weight gain among female college students (2011). Researchers modified a Healthy Weight intervention that previously had shown reduced eating disorder symptoms, reduced BMI, reduced obesity onset, and reduced eating disorder onset relative to assessment only controls. Modifications to this program included adding nutrition principals taken from nutrition research to increase the facilitation of healthy dietary changes and adding principals that encouraged increased physical activity. Stice et al. named this intervention "Healthy Weight 2". Results showed that compared to the healthy weight brochure control group, all eating disorder risk factors significantly greater improvements from pre-to-post survey. However, intervention effects of BMI at 2- and 3-year follow-ups were non-significant.

With that in mind, one of the greatest health-related challenges that society faces today is obesity. The negative health risks associated with obesity include type 2 diabetes, dyslipidemia, 
coronary artery disease, cancer, among others (Nia et al., 2011). Although eating disorders and obesity are not one in the same, there is an undeniable relationship that exists between these conditions. Emerging literature has begun to identify consistencies among eating behaviors that may predict obesity and eating disorder onset. Recent literature reveals that lifetime eating disorder prevalence is highest among individuals with binge-eating disorder who are either overweight or obese (Duncan, Ziobrowski, \& Nicol, 2017). Specifically, individuals with a BMI greater than 40 (class III obesity) are more likely to have a life-long diagnosis of binge eating disorder. Can both obesity and eating disorders be addressed simultaneously? That question has yet to be definitively answered and is quite complex in its nature.

Dr. Neumark-Sztainer (2005) critically analyzed the literature on approaches to eating disorder and prevention and addressed the fear that targeting one condition might unintentionally lead to the other. These issues should be viewed on a weight-related disorder continuum. Dr. Neumark-Sztainer (2005) researched adolescents to identify shared risk factors for becoming overweight/obese and developing eating disorders. Weight-testing by parents and family members, personal weight concerns, and unhealthy weight control behaviors consistently predicted overweight status and binge eating at long-term follow-ups. Furthermore, childhood obesity has consistently been identified as a risk factor for developing an eating disorder later in life (Burrows, A. \& Cooper, M., 2002). Limited studies have examined the long-term consequences that obesity during childhood can have later in life in regards to the development of eating disorders, likely due to challenges associated with longitudinal studies. Pre-adolescent obesity prevention programs are much more common than eating disorder prevention programs. As relationships between the two continue to be identified, intervention strategies that take both 
conditions into consideration may lead to improved outcomes for obesity and eating disorder prevention.

These theories pose many questions as to the most effective way to not only prevent eating disorders, but also improve all weight-related disorders as they are interrelated in ways that are still unclear. Research suggests that childhood and adolescent obesity causes a predisposition for developing eating disorders such as bulimia nervosa and binge eating disorder (Fairburn et al., 1997). Roehrig, Thompson, and Cafri (2008) examined the short-term effects of dieting related to psychoeducational messages on risk factors for eating pathology and weight control variables. Participants were randomly assigned to three conditions, receiving either a prodieting, antidieting, or control message intervention. The antidieting message yielded significant reductions in bulimic intentions. Healthy eating significantly increased from baseline to follow-up tests along with dieting intentions and perceived pressure to lose weight. They found that feeling pressure to lose weight in the prodieting condition caused increased weight control intentions, negative-affect, and body dissatisfaction (Roehrig, Thompson, Cafri, 2008). This implies that while the promotion of dieting can help people eat healthier and potentially decrease body mass index, there is an extremely delicate balance in addressing obesity without increasing eating disorder risk factors.

\section{Conclusions}

Eating disorders have the highest mortality rate of any mental illness (Smink, Hoeken, \& Hoek, 2012) and should be considered an important public health concern because they are typically accompanied with other psychological impairments and highly undertreated (Hudson, et al., 2008). There is ample evidence supporting the Body Project's effectiveness in decreasing risk factors associated with eating disorders, specifically binge-eating disorder through 
dissonance practices that encourage participants to challenge the thin-ideal. However, the Body Project has not shown consistent evidence that the intervention will produce long-term decreases unhealthy weight gain. Findings from healthy weight intervention efficacy trials generally show superiority over dissonance-based programs in decreasing body mass index and preventing unhealthy weight gain, though healthy weight trials show little effects on depressive symptoms (Stice et al., 2012; McMillan, Stice, \& Rohde, 2011). Also, examining if differences in peerfacilitator demographics and qualifications would impact intervention effects is needed to further the current understanding of the effectiveness of peer-lead dissonance-based eating disorder prevention program groups. For instance, intervention outcomes may improve by recruiting individuals that have previous experience leading groups or are entering the psychology field. The information gathered from the literature helped to generate the research questions for this study that addressed the effectiveness of dissonance-based eating disorder programs on decreasing eating disorder risk factors and whether BMI had any impact on the effectiveness of the eating disorder prevention program. 


\section{References}

Academy for Eating Disorders. Fast facts on eating disorders: Causes. Retrieved on March $10^{\text {th }}, 2017$. https://www.aedweb.org/index/php/education/eating-disorder-information.

Alkinson, M. J. \& Wade, T. D. (2015). Mindfulness-based prevention for eating disorders: A school-based cluster randomized controlled study. International Journal of Eating Disorders, 48, 1024-1037. DOI:10.1002/eat.22416.

Anorexia Nervosa and Related Eating Disorders. Statistics: How many people have eating disorders? Retrieved on March 10 ${ }^{\text {th }}, 2017$. https://www.anred.com/stats.html.

Arcelus, J., Mitchell, A. J., Wales, J., \& Nielsen, S. (2011). Mortality rates in patient with anorexia nervosa and other eating disorders. A meta-analysis of 36 studies. Archives of General Psychiatry, 68(7), 724-731. DOI: 10.1001/archgenpsychiatry.2011.74.

Argyrides, M. \& Kkeli, N (2014). Predictive factors of disordered eating and body image satisfaction in cyprus. International Journal of Eating Disorders, 48(4), 431435.DOI:10.1002/eat.22310.

Austin, B. S., Field, A. E., \& Wiecha, J. (2005). The impact of a school-based obesity prevention trial on disordered weight-control behaviors in Early Adolescent Girls. Archives of Pediatric and Adolescent Medicine, 159(3), 225-230. DOI:10.1001/archpedi.159.3.225.

Becker, C. B., Bull, S., Schaumberg, K., Cauble, A., Franco, A. (2008). Effectiveness of peer-led eating disorder prevention: A replication trial. Journal of Consulting Clinical Psychology, 76, 347-354. 
Becker CB, Bull S, Schaumberg K, Cauble A, Franco A. Effectiveness of peer-led eating disorders prevention: A replication trial. Journal of Consult in Clinical Psychology, $2008 ; 76,347-353$.

Becker C. B., Smith L. M., Ciao A. C. (2006). Peer facilitated eating disorders prevention: A randomized effectiveness trial of cognitive dissonance and media advocacy. Journal of Counseling Psychology, 53, 550- 555.

Berge, J. M., Loth, K., Hanson, C., Croll-Lampert, J., \& Neumark-Sztainer, D. (2012). Family life cycle transitions and the onset of eating disorders: a retrospective grounded theory approach. Journal of Clinical Nursing, 21(9-10):1355-1363. DOI: 10.1111/j.13652702.03762.x.

Bryant, R. A., Harvey, A. G., \& Tarrier, N. (2003). Cognitive behavioral therapy for posttraumatic stress disorder. Clinical Psychology Review, 23, 501-522.

Cools, J., Schotte, D. E., McNally, R. J. (1992). Emotional arousal and overeating in restrained eaters. Journal of Abnormal Psychology, 101(2), 348-351.

Corning, A. F., Bucchianeri, M. M., \& Pack, C. M. (2014). Thin or overweight women's fat talk: Which is worse for other women's body satisfaction? Eating Disorders, 22(121135). Doi:1080/10640266.2013.860850.

Duncan, A. E., Ziobrowski, H. N., \& Nicol, G. (2017). The prevalence of past 12-month and lifetime DSM-IV eating disorders by BMI category in US men and women.

Evans, E. H., Adamson, A. L., Basterfield, L., Le Couteur, A., Reilly, J. K., Reilly, J. J., \& Parkinson, K. N. (2016). Risk factors for eating disorder symptoms at 12 years of age: A 6-year longitudinal cohort study. Appetite, 108, 12-20. DOI:10.1016/j.appet.2016.09.005. 
Fairburn, C.G., Welch, S.L., Doll, H.A., Davies, B.A., \& O’Connor, M.E. (1997). Risk factors for bulimia nervosa: A community-based case control study. Archives of General Psychiatry, 54(6), 509-517.

Festinger, L. (1964). Postdecision changes in the desirability of alternatives. The Journal of Abnormal and Social Psychology, 59(2), 177.

Festinger, L. \& Carlsmith, J. M. (1959). Cognitive consequences of forced compliance. Journal of Abnormal and Social Psychology, 58, 203-210.

Frederique, V. E., Giampietro, V., Simmons, A., Uher, R., Andrew, C. M., Philippe-Oliver, H., Campbell, I. C., \& Schmidt, U. (2013). Brain responses to body image stimuli but not food are altered in women with bulimia nervosa. BioMed Central Psychiatry, 13:302. DOI:1186/1471-244X-13-302.

Goldschmidt, A. B., Wall, M. M., Zhang, J., Loth, K. A., \& Neumark-Sztainer, D. (2016). Overeating and binge eating in emerging adulthood: 10-year stability and risk factors. Developmental Psychology, 52(3), 475-483. DOI:10.1037/dev0000086.

Hart, L. M., Cornell, C., Damiano, S. R. \& Paxton, S. J. (2015). Parents and prevention: A systematic review of interventions involving parents that aim to prevent body dissatisfaction or eating disorders. International Journal of Eating Disorder, 48, 157169. Doi:10.1002/eat.22284.

Hudson, J. I., Hiripi, E., Pope, H. G., \& Kesslet, R. C. (2008). The prevalence and correlated of eating disorder in the national comorbidity survey replication. Journal of Biological Psychiatry, 61(3), 348-356.

Hughes, Jan H. (1983). The application of cognitive dissonance theory to consultation. Journal of School Psychology, 21(4), 349-357. 
Keel, P. K., Mitchell, J. E., Davis, T. L., \& Crow, S. J. (2000). Relationship between depression and body dissatisfaction in women diagnosed with bulimia nervosa. International Journal of Eating Disorders, 30, 48-56.

Manaf, N. A., Saravanan, C., \& Zuhrah, B. (2016). The prevalence and inter-relationship of negative body image perception, depression, and susceptibility to eating disorders among female medical undergraduate students. Journal of Clinical and Diagnostic Research, 10(3):VCD1-VCD4. DOI:10.7860/JCDR/2016/16678.7341.

McKimmie, B. M. (2015). Cognitive dissonance in groups. Journal of Social and Personality Psychology Compass, 10, 202-212.

Neumark-Sztainer, D. R., Wall, M. M., Haines, J. I., Story, M. T., Sherwood, N. E., \& van den Burg, P., A. (2007). Shared risk and protective factors for overweight and disordered eating in adolescents. American Journal of Preventative Medicine, 33(5), 359-369.

Mitchell, N., Catenacci, V., Obesity, an overview of an epidemic. 34(4), 717-732. DOI:10:1016/j.psc.2011.08.005.

National Eating Disorder Association (NEDA). Types and Symptoms of Eating Disorders. Retrieved on January $10^{\text {th }}, 2017$. https://www.nationaleatingdisorders.org/types- symptoms-eating-disorders.

National Eating Disorder Collaboration. What is bulimia nervosa? Retrieved on January 22nd, 2017. http://www.nedc.com.au/bulimia-nervosa.

Neumark-Sztainer, D \& Hannan, P. J. (2000). Weight-related behaviors among adolescent girls and boys: results from a national survey. Archives of Pediatric and Adolescent Medicine, 154(6): 569-577. 
Smink, F. E., Hoeken, D., \& Hoek, H. W. (2012). Epidemiology of eating disorders: Incidence, prevalence, and mortality rates. Current Psychiatry Reports, 14(4), 406-414.

Stice, E. (2001). A prospective test of the dual-pathway model of bulimic pathology: Mediating effects of dieting and negative affect. Journal of Abnormal Psychology, 110(1), 124-135.

Stice, E., Butryn, M. L., Rohde, P., Shaw, H., \& Marti, N. (2013). An effectiveness trial of a new enhanced dissonance eating disorder prevention program among female college students. Behavior Research and Therapy, 51, 862-871.

Stice, E., Marti, N. C., Rohde, P., \& Shaw, H. (2011). Testing mediators hypothesized to account for the effects of a dissonance eating disorder prevention program over longer-term follow-up. Journal of Consulting and Clinical Psychology, 79(3), 398-405.

Doi:10.1037/a0023321.

Stice, E., Marti, N. C., Spoor, Sonja., Presnell, K., \& Shaw, H. (2008). Dissonance and healthy weight eating disorder prevention programs: Long-term effects from a randomized efficacy trial. Journal of Consulting and Clinical Psychology, 76(2), 329-340. Doi:10.1037/0020-006X.76.2.329.

Stice, E., Rohde, P., Durant, S., Shaw, H., \& Wade, E. (2013). Effectiveness of peer-led dissonance-based eating disorder prevention groups: Results from two randomized pilot trials. Behavior Research and Therapy, 51, 197-206.

Stice, E., Rohde, P., Gau, J., \& Shaw, H. (2009). An effectiveness trial of a dissonance-based eating disorder prevention program for high-risk adolescent girls. Journal of Consulting and Clinical Psychology, 77(5), 825-834. Doi:10.1037/a00016132.

Stice, E., Rohde, P., Shaw, H., \& Gau, J. (2011). An effectiveness trial of a selected dissonancebased eating disorder prevention program for female high school students: Long-term 
effects. Journal of Consulting and Clinical Psychology, 79(4), 500-508. Doi:

10:1037/a0024351.

Stice, E., Rohde, P., Shaw, H., \& Marti, C. N. (2011). Efficacy trial of a selective prevention program targeting both eating disorder symptoms and unhealthy weight gain among female college students. Journal of Consulting and Clinical Psychology. 24, 421-429. Doi:10.1037/a0026484.

Stice, E., Rohde, P., \& McMillan, W. (2011). High and low-level dissonance-based eating disorder prevention program with you women with body image concerns: an experimental trial. Journal of Consulting and Clinical Psychology, 79(1), 129-134.

Stice, E., Shaw, H., Burton, E., \& Wade, E. (2006). Dissonance and healthy weight eating disorder prevention programs: A randomized efficacy trial. Journal of Consulting and Clinical Psychology, 74(2), 263-275.

Stice, E. \& Shaw, H. (2007). Testing mediators of intervention effects in randomized controlled trials: An evaluation of two eating disorder prevention programs. Journal of Consulting and Clinical Psychology, 75(1), 20-32. Doi:10.1037/0022-006X.75.1.20.

Stice, E. \& Shaw, H. (2008). Dissonance-based interventions for the prevention of eating disorders: Using persuasion principals to promote change. Preventative Science, 9, 114128. Doi:10:1007/s11121-088-0093.

Taylor, B. C., Trockel, M., Cunning, D., Bailey, J., Aspen, V., Jacobi, C., Kass, A., Weisman, H., Sinton, M., Schecthman, K., \& Wilfley, D. E. (2016). Reducing eating disorder onset in a very high risk sample with significant comorbid depression: a randomized control trial. Journal of Counseling and Clinical Psychology, 84(5), 402-414. 
Thompson, J., K., Heinburg, L., J., Altable, M. N., \& Tantleff-Dunn, S. (1999). Exacting beauty: Theory, assessment, and treatment of body image disturbances. American Psychological Association. 369 pages.

Wilfley, D. E., Citrome, L., \& Jerman, B. K. (2016). Characteristics of binge eating disorder in relation to diagnostic criteria. Neuropsychiatric Disease and Treatment, 12, 2213-2223. DOI:10.2147/NDT.S107777. 


\section{APPENDIX A: BODY PROJECT PRE/POST SURVEY}

$*$ titles of sections (arrowed and underlined) were not present on surveys used in real-life,
but were added for ease of identification in this report
$*$ only sections of the survey that were analyzed in the current study were included in this
appendix

Ideal-thin Internalization

Please circle the response that reflects your agreement strongly disagree neutral agree strongly with these statements over the past month:

1. Slim women are more attractive ........................................

2. Tall women are more attractive disagree agree

3. Women with toned bodies are more attractive 1

4. Women who are in shape are more attractive $\ldots 1$

5. Slender women are more attractive

6. Women with long legs are more attractive

7. Women with big breasts are more attractive

$\begin{array}{lllr}2 & 3 & 4 & 5 \\ 2 & 3 & 4 & 5 \\ 2 & 3 & 4 & 5 \\ 2 & 3 & 4 & 5 \\ 2 & 3 & 4 & 5 \\ 2 & 3 & 4 & 5 \\ 2 & 3 & 4 & 5 \\ 2 & 3 & 4 & 5\end{array}$

8. Women with shapely butts are more attractive.

\section{DietRestraint}

Circle the best response to describe your behavior never seldom some often always over the last month:

1. If you put on weight, did you eat less than you normally would? $\ldots . . .1 \quad 2 \quad \begin{array}{lllll}3 & 4 & 5\end{array}$

2. Did you try to eat less at mealtimes than you would like to eat?.........1 $\quad 2 \quad 3 \quad 4 \quad 5$

3. How often did you refuse food or drink because you were concerned about your weight

$\begin{array}{lllll}1 & 2 & 3 & 4 & 5\end{array}$

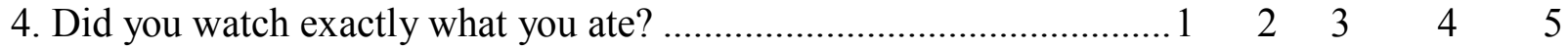

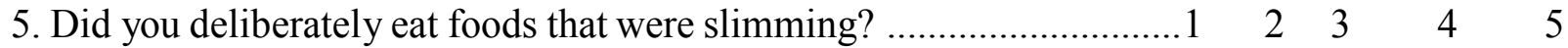

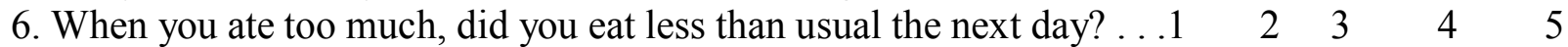

7. Did you deliberately eat less in order not to become heavier? ............ $1424 \quad 3 \quad 4 \quad 5$

8 . How often did you try not to eat between meals because you were watching your weight?

9. How often in the evenings did you try not to eat because you were watching your weight?

10. Did you take into account your weight in deciding what to eat?

$\begin{array}{lllll}1 & 2 & 3 & 4 & 5\end{array}$

\section{Body Dissatisfaction}

\begin{tabular}{|c|c|c|c|c|c|}
\hline $\begin{array}{l}\text { Over the past month, how satisfied } \\
\text { were you with your: }\end{array}$ & $\begin{array}{l}\text { extremely } \\
\text { dissatisfied }\end{array}$ & $\begin{array}{l}\text { moderately } \\
\text { dissatisfied }\end{array}$ & neutral & $\begin{array}{c}\text { moderately } \\
\text { satisfied }\end{array}$ & $\begin{array}{r}\text { extremely } \\
\text { satisfied }\end{array}$ \\
\hline 1. Weight $\ldots \ldots \ldots \ldots \ldots \ldots$ & 1 & 2 & 3 & 4 & 5 \\
\hline 2. Figure................. & 1 & 2 & 3 & 4 & 5 \\
\hline 3. Appearance of stomach. ......... & 1 & 2 & 3 & 4 & 5 \\
\hline 4. Body build. . . . . . . . . & 1 & 2 & 3 & 4 & 5 \\
\hline 5. Waist .... & 1 & 2 & 3 & 4 & 5 \\
\hline 6. Thighs . & 1 & 2 & 3 & 4 & 5 \\
\hline 7. Buttocks. & 1 & 2 & 3 & 4 & 5 \\
\hline
\end{tabular}




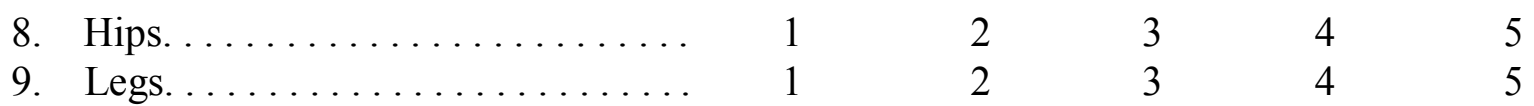

\section{Negative Affect}

Please circle the response that indicates how you have felt during the pastweek.

a little moderately a lot extremely

1. Disgusted with self .... 1

$\begin{array}{llll}2 & 3 & 4 & 5\end{array}$

2. Sad.............. 1

3. Afraid ............ 1

4. Shaky. ........... 1

$\begin{array}{llll}2 & 3 & 4 & 5\end{array}$

5. Alone. ........... 1

6. Blue............. 1

7. Guilty .......... 1

8. Nervous.......... 1

9. Lonely. .......... 1

10. Jittery. . . . . . . . . 1

11. Ashamed ......... 1

12. Scared ........... 1

13. Angry at self . . . . . . 1

14. Downhearted. . . . . . . 1

15. Blameworthy. ...... 1

16. Frightened ......... 1

17. Dissatisfied with self. . 1

18. Anxious. . . . . . . . . . 1

19. Depressed ........ 1

20. Worried .......... 1

2

2

$\begin{array}{lll}3 & 4 & 5\end{array}$

345

$\begin{array}{llll}2 & 3 & 4 & 5\end{array}$

$\begin{array}{llll}2 & 3 & 4 & 5 \\ 2 & 3 & 4 & 5\end{array}$

$\begin{array}{llll}2 & 3 & 4 & 5\end{array}$

$\begin{array}{llll}2 & 3 & 4 & 5\end{array}$

$\begin{array}{llll}2 & 3 & 4 & 5\end{array}$

$\begin{array}{llll}2 & 3 & 4 & 5\end{array}$

$\begin{array}{llll}2 & 3 & 4 & 5 \\ 2 & 3 & 4 & 5\end{array}$

$\begin{array}{llll}2 & 3 & 4 & 5\end{array}$

$\begin{array}{llll}2 & 3 & 4 & 5\end{array}$

$\begin{array}{llll}2 & 3 & 4 & 5\end{array}$

$\begin{array}{llll}2 & 3 & 4 & 5\end{array}$

$\begin{array}{llll}2 & 3 & 4 & 5\end{array}$

$\begin{array}{llll}2 & 3 & 4 & 5\end{array}$

$\begin{array}{llll}2 & 3 & 4 & 5 \\ 2 & 3 & 4 & 5 \\ 2 & 3 & 4 & 5\end{array}$

Eating Disorder Symptoms Related to Body Image

Over the pastmonth...

1. Have you felt fat?..............

2. Have you had a definite fear that you

might gain weight or become fat?........

3. Has your weight influenced how you think about (judge) yourself as a person?........ 4. Has your shape influenced how you think about (judge) yourself as a person?........

\section{Bodv Mass Index}

19. How much do you weigh? If uncertain, please give your best estimate. lbs.

20. How tall are you?_Please specify in inches ( $5 \mathrm{ft} .=60 \mathrm{in}$.) in. 


\section{APPENDIX B: RECRUITMENT LETTER}

Dear Student,

Are you tired of being unhappy with your body? Would you be happier if you could learn to let go of unrealistic expectations about how you are supposed to look? Would you like to promote healthy body image to others? If so, register today for the Body Project, a leadership and healthy body image program for women offered by Student Counseling Services and Health Promotion \& Wellness.

The Body Project is a very effective peer-led program that teaches college women how to combat the unrealistic, ultra-thin ideal portrayed by the media. The program helps participants develop and maintain positive body image through a variety of media literacy and self-awareness exercises. Through fun activities and engaging discussion, participants will learn how to counter fat talk in daily life, embrace the healthy ideal and their own body image, engage in body activism, and appreciate the non-appearance related aspects of themselves and others.

The Body Project program will be offered to Illinois State University college women throughout the spring semester. The options are listed below:

Body Project General Implementations:

- Mondays, February 6 and 13 from 6-8 p.m. - Hewitt/Manchester Hall, Escalante Room

- Tuesdays, February 21 and 28 from 2-4 p.m. - Student Services Building, Room 304

- Wednesdays, February 22 and March 1 from 6-8 p.m. - Student Services Building, Room 376

- Tuesdays, March 21 and 28 from 5-7 p.m. - Student Services Building, Room 304

All participants who complete both sessions will earn a Body Project Certificate of Completion and water bottle. Students may also earn credit towards the ISU Leads Certificate - Civic Engagement Pillar.

Pre-registrationisrequired. For more information, please contact Dr.JenniThome, Eating Disorder and Body Image Outreach Coordinator, Student Counseling Services, or JimAlmeda, Health Promotion and Wellness.

We hope to see you soon! 